\title{
A composição florística e a diversidade de pteridófitas diferem entre a Floresta de Restinga e a Floresta Ombrófila Densa das Terras Baixas do Núcleo Picinguaba/PESM, Ubatuba/SP?
}

\author{
Giseli Areias Nóbrega ${ }^{1,6}$, Pedro Vasconcellos Eisenlohr ${ }^{1}$, \\ Mateus Luis Barradas Paciência ${ }^{3}$, Jefferson Prado ${ }^{4}$ \& Marcos Pereira Marinho Aidar ${ }^{5}$ \\ IPrograma de Pós-Graduação em Biologia Vegetal, Universidade Estadual de Campinas - UNICAMP, \\ CP 6109, CEP 13083-970, Campinas, SP, Brasil \\ 2Instituto de Botânica, Setor de Fisiologia Vegetal, CP 4005, CEP 04301-012, São Paulo, SP, Brasil \\ ${ }^{3}$ Laboratório de Extração, Herbário, Universidade Paulista - UNIP, CEP 01310-100, São Paulo, SP, Brasil \\ ${ }^{4}$ Instituto de Botânica, Setor de Briologia e Pteridologia, CP 4005, CEP 04301-012, São Paulo, SP, Brasil \\ ${ }^{5}$ Instituto de Botânica, Setor de Fisiologia Vegetal, CP 4005, CEP 04301-012, São Paulo, SP, Brasil \\ ${ }^{6}$ Autor para correspondência: Giseli Areias Nóbrega, e-mail: giareias@gmail.com
}

NÓBREGA, G.A., EISENLOHR, P.V., PACIÊNCIA, M.L.B., PRADO, J. \& AIDAR, M.P.M. Ferns composition and diversity differ between Restinga and Lowland Rainforest areas in the Serra do Mar? Biota Neotrop. 11(2): http://www.biotaneotropica.org.br/v11n2/en/abstract?article+bn02911022011

\begin{abstract}
Ferns are an important component of the tropical flora, representing about $10 \%$ of all vascular plants of tropical forests, constituting the dominant group among the herbaceous vegetation. The aim of this study was to determine whether the ferns communities in two areas of Atlantic Forest, Restinga (FRS) and Lowland Ombrophilous Dense (FTB) forests, located on soils remarkably distinct and separated by a highway, differ in their floristic composition and diversity. These two faces are located in Picinguaba locality, Parque Estadual da Serra do Mar, Ubatuba, São Paulo ( $23^{\circ} 31^{\prime}$ to $23^{\circ} 34^{\prime} \mathrm{S}$ and $45^{\circ} 02^{\prime}$ to $45^{\circ} 05^{\prime} \mathrm{W}$ ). We delimited seven plots of $20 \times 20 \mathrm{~m}$ in each area, collected, identified and listed the fern individuals. We performed three methods of multivariate analysis (TWINSPAN, UPGMA and PCO) to verify the existence of floristic groups; calculated the Payandeh index to define the level of aggregation of each species in each of the two areas (FRS and FTB); obtained indicator species for each area; and performed diversity analysis (richness, evenness and heterogeneity). The two areas sampled 3482 individuals, 1366 of which occur in FRS and 2116 in FTB. We found 14 species in FRS and 29 in FTB; these areas shared five species. We found two well-defined floristic blocks $($ FRS $\times$ FTB $)$ in cluster analysis. In the FRS, relatively most species showed aggregated distribution and fewer species showed random distribution in relation to FTB. We found four indicator species for FRS and eight for FTB. The curves resulting from the individual-based rarefaction indicated a strong difference in species richness between the two communities, in favor to FTB. These differences may be related to physical and chemical characteristics of soil (more fertile and less toxic in the FTB), water dynamics (plant species in the FRS are generally subject to water stress) and the sharp break caused by highway that cuts through the park. These aspects could be related to different forms of occupation of niches and to the fact that some species in environments with limited resources and heterogeneously distributed in space, such as the studied Restinga, would eliminate the others.
\end{abstract}

Keywords: edaphic parameters, environmental selection, multivariate analysis, species richness.

NÓBREGA, G.A., EISENLOHR, P.V., PACIÊNCIA, M.L.B., PRADO, J. \& AIDAR, M.P.M. A composição florística e a diversidade de pteridófitas diferem entre a Floresta de Restinga e a Floresta Ombrófila Densa das Terras Baixas do Núcleo Picinguaba/PESM, Ubatuba/SP? Biota Neotrop. 11(2): http://www. biotaneotropica.org.br/v11n2/pt/abstract?article+bn02911022011

Resumo: As pteridófitas constituem um componente importante da flora tropical, representando aproximadamente $10 \%$ do total de plantas vasculares de florestas tropicais, sendo o grupo dominante entre a vegetação herbácea. O objetivo do trabalho foi verificar se as comunidades de pteridófitas de duas áreas de Mata Atlântica, Floresta de Restinga (FRS) e Floresta Ombrófila Densa de Terras Baixas (FTB), situadas sobre solos notavelmente distintos e separadas por uma grande rodovia, difeririam em sua composição florística e diversidade. Estas duas fisionomias estão localizadas no Núcleo Picinguaba do Parque Estadual da Serra do Mar, Ubatuba, São Paulo $\left(23^{\circ} 31^{\prime}\right.$ a $23^{\circ} 34^{\prime} \mathrm{S}$ e $45^{\circ} 02^{\prime}$ a $\left.45^{\circ} 05^{\prime} \mathrm{W}\right)$. Em cada área delimitamos sete parcelas de $20 \times 20 \mathrm{~m}$, nas quais os indivíduos foram coletados, identificados e recenseados. Efetuamos três métodos de análise multivariada (TWINSPAN, UPGMA e PCO) para verificar a existência de grupos florísticos; calculamos o índice de Payandeh para definirmos o nível de agregação de cada espécie em cada uma das duas áreas (FRS e FTB); obtivemos espécies indicadoras para cada área; e realizamos análises de diversidade (riqueza, equabilidade e heterogeneidade). Nas duas áreas amostramos 3.482 indivíduos, dos quais 1.366 ocorrem na FRS e 2.116 na FTB. Encontramos 14 espécies na FRS e 29 na FTB; cinco espécies foram compartilhadas entre as duas áreas. As análises de grupos 
florísticos mostraram a formação de dois blocos bem definidos (FRS $\times$ FTB). Na FRS, relativamente mais espécies apresentaram distribuição agregada e menos espécies apresentaram distribuição aleatória em relação à FTB. Encontramos quatro espécies indicadoras para a FRS e oito para a FTB. As curvas resultantes da rarefação por indivíduos indicaram forte diferença de riqueza específica entre as duas comunidades, favorável à FTB. As diferenças encontradas podem estar relacionadas às características físico-químicas do solo (mais fértil e menos tóxico na FTB), à dinâmica da água (as espécies vegetais da FRS estão, de modo geral, sujeitas ao estresse hídrico) e ao impacto causado pela estrada que corta o Parque. Esses aspectos poderiam estar relacionados a diferentes formas de ocupação de nichos e ao fato de que algumas espécies em ambientes com recursos limitados e distribuídos heterogeneamente no espaço, como é o caso da Restinga estudada, eliminariam as demais.

Palavras-chave: parâmetros edáficos, seletividade ambiental, análises multivariadas, riqueza de espécies.

\section{Introdução}

Nas regiões tropicais de todo o mundo, as pteridófitas são encontradas desde o nível do mar até o limite da vegetação altimontana (Windisch 1990), ocorrendo principalmente nas florestas úmidas. As pteridófitas possuem capacidade de dispersão e migração pouco variáveis (Tryon 1986), fazendo com que tenham elevado potencial como indicadoras ambientais (Tuomisto \& Poulsen 1996). Pesquisas têm revelado que estas plantas podem indicar diferentes condições edáficas (Tuomisto \& Ruokolainen 1994, Tuomisto et al. 1995, Tuomisto \& Poulsen 1996), ambientes alterados (Tuomisto et al. 1995, Ruokolainen et al. 1997) e estágios distintos de regeneração florestal, mediante a associação da comunidade a diferentes tipos de vegetação (Poulsen \& Baslev 1991, Paciência 2008).

As pteridófitas constituem um componente importante da flora tropical (Foster 1990, Ricci 1996). Em diferentes ecossistemas alguns estratos das florestas, como o sub-bosque, são dominados por espécies desse grupo (León \& Yong 1996, Arens \& Baracaldo 1998). De acordo com Grayum \& Churchill (1987) e Gentry (1990), as pteridófitas representam aproximadamente $10 \%$ do total de plantas vasculares de florestas tropicais, sendo o grupo dominante entre a vegetação herbácea (Foster 1990, Foster \& Hubbell 1990, Hammel 1990) e contribuindo significativamente para a diversidade das florestas tropicais (Grayum \& Churchill 1987). Há duas hipóteses para explicar a diversidade das pteridófitas. A primeira é baseada no modelo de "dispersão aleatória" (Hubbell 2001), que prevê que as espécies seriam competitivamente idênticas e as diferenças florísticas seriam limitadas pela dispersão das espécies. A segunda hipótese é a da diferenciação de nicho ou "heterogeneidade ambiental" (Tuomisto et al. 2003), segundo a qual os fatores ambientais existentes na área de ocorrência das espécies (solos, estrutura física, microclima etc.) seriam capazes de selecionar as espécies mais aptas a sobreviver frente ao conjunto resultante dessa heterogeneidade. Os solos parecem ter papel fundamental nesse sentido, como sugerido por Young \& Léon (1989) e Poulsen \& Baslev (1991), que encontraram forte relação entre diversidade beta de pteridófitas, sua distribuição e características edáficas. Além disso, os efeitos de rompimentos abruptos entre ecossistemas, como os provocados pela existência de estradas, podem ocasionar alterações na distribuição e na diversidade das espécies desse grupo (Paciência \& Prado 2004, 2005a,b, Santiago et al. 2004, Faria et al. 2009), principalmente na história natural recente dessas regiões, podendo favorecer a segregação florística entre as comunidades situadas em cada lado.

Há quatro regiões com alta diversidade de espécies de pteridófitas na América Tropical, cada uma delas com aproximadamente $40 \%$ de espécies endêmicas. O Brasil é uma dessas regiões (Tryon \& Tryon 1982), constituindo-se num dos principais centros de endemismo e especiação do continente americano e do mundo. No país, as espécies são encontradas predominantemente nas áreas de domínio da Floresta Atlântica (Labiak \& Prado 1998), apresentando altos índices de diversidade e endemismo (Tryon 1972). A principal formação costeira da Mata Atlântica, a Floresta Ombrófila Densa, é a segunda maior floresta da região neotropical. Apresenta-se subdividida, segundo a classificação proposta pelo IBGE (Veloso et al. 1991), em cinco formações. $\mathrm{Na}$ faixa entre $16^{\circ}$ e $24^{\circ} \mathrm{S}$, entre 5 e $50 \mathrm{~m}$ de altitude, ocorre a Floresta Ombrófila Densa das Terras Baixas e, geralmente próximo a essa formação, ocorrem as florestas de restinga. Essas duas formações são o foco do nosso trabalho e seus aspectos centrais são discutidos por Assis et al. (2011).

Embora pudessem ser úteis para o conhecimento de possíveis respostas das espécies de pteridófitas ao ambiente em que se inserem, trabalhos comparando comunidades desse grupo de plantas entre terras baixas e restingas não foram encontrados. Investigar os fatores ligados a essas respostas significa investigar também a distribuição, o crescimento e a morfologia de diversas espécies de pteridófitas (Ricci 1996, Barnarde et al. 1999). Alguns dos mais importantes fatores que poderiam alterar esses aspectos das comunidades vegetais (incluindo as de pteridófitas) são a intensidade luminosa, a temperatura, a pluviosidade, a umidade relativa do ar, a capacidade de retenção de água do substrato e o teor de nutrientes deste, os quais são potencialmente variáveis entre ambientes como as florestas de restinga e de terras baixas (Conway \& Stephens 1957, Dias-Filha 1989).

Estudos realizados entre 2005 e 2008 pela Fundação SOS Mata Atlântica (2009) mostraram que restam apenas 11,41\% da cobertura original da Mata Atlântica e somente uma pequena parte está incluída em áreas de preservação ambiental (15\% de remanescentes no Estado de São Paulo). Considerando a necessidade de se contribuir para práticas de conservação nesse hotspot (Myers et al. 2000), este trabalho investigou possíveis diferenças na composição e diversidade entre duas áreas (florestas de restinga e de terras baixas) da Serra do Mar, uma unidade de conservação que abriga a maioria das espécies endêmicas de pteridófitas da Floresta Atlântica (Tryon 1972). Assis et al. (2011) trabalharam nessas mesmas áreas e encontraram diferenças consistentes para a comunidade arbórea, na qual predominam as angiospermas. Ambos os trabalhos fazem parte do Projeto "Composição florística, estrutura e funcionamento da Floresta Ombrófila Densa dos Núcleos Picinguaba e Santa Virgínia do Parque Estadual da Serra do Mar" - BIOTA Gradiente Funcional (FAPESP 03/12595-7).

Testamos a hipótese de que o grupo de pteridófitas dessas duas áreas difere em sua composição florística e diversidade. Seria essa expectativa suportada em contraposição à possibilidade de um amplo compartilhamento de espécies, que poderia ocorrer pelo fato de ambas as áreas estarem situadas na mesma unidade de conservação e a uma distância relativamente pequena $(3 \mathrm{~km})$ entre si?

As seguintes perguntas nortearam nossa investigação: 1) Os padrões florísticos das espécies de pteridófitas variam entre florestas 
de restinga e de terras baixas na Serra do Mar? Esperamos que, frente às fortes variações de solos (Assis et al. 2011), haja baixa similaridade entre as duas comunidades e que cada uma apresente um padrão de distribuição espacial diferente da outra. 2) Considerando a região amostrada, quais são as espécies indicadoras de cada comunidade? 3) A restinga, que se desenvolve em um ambiente edáfico mais restritivo, apresenta diversidade de espécies inferior em relação às terras baixas? Considerando o potencial indicador das espécies de pteridófitas, eventuais variações na composição e na diversidade entre essas duas áreas ajudariam a mostrar quão diferentes elas são e revelariam a importância de tratá-las como entidades florísticas distintas em futuros projetos de restauração e manejo de florestas costeiras.

\section{Material e Métodos}

\section{1. Áreas de estudo}

Desenvolvemos o trabalho em duas fisionomias da Mata Atlântica, as quais, segundo as características encontradas na localidade de estudo, são denominadas por Veloso et al. (1991) como Floresta Ombrófila Densa Aluvial e Floresta Ombrófila Densa de Terras Baixas. Seguindo o $1^{\circ}$ relatório do BIOTA Gradiente Funcional, as áreas aqui estudadas foram, por questões fisionômicas, denominadas respectivamente como Floresta de Restinga (FRS), formação florestal que ocorre sobre os cordões arenosos do litoral, em altitudes que variam de 0 a 50 m, e Floresta Ombrófila Densa das Terras Baixas (FTB), formação florestal que recobre o sopé da Serra do Mar (piemonte), em altitudes que variam de 50 a $100 \mathrm{~m}$ de altitude, e ocorre sobre solos originários da sedimentação de material oriundo da erosão das áreas mais elevadas da Serra do Mar.

Estas duas fisionomias estão localizadas no Núcleo Picinguaba do Parque Estadual da Serra do Mar, Ubatuba, São Paulo (23 $31^{\prime}$ a $23^{\circ} 34^{\prime} \mathrm{S}$ e $45^{\circ} 02^{\prime}$ a $45^{\circ} 05^{\prime} \mathrm{W}$ ), que apresenta cerca de 47.500 ha. O clima regional é tropical úmido, sem estação seca (Setzer 1966), com precipitação média anual superior a $2.200 \mathrm{~mm}$. Segundo Lacerda (2001), os solos do Núcleo Picinguaba são em geral ácidos e com altos níveis de matéria orgânica e alumínio. Os solos da FTB mostram-se, porém, mais férteis que os da FRS, com maiores teores de bases e capacidade de troca catiônica e menor saturação por alumínio (Assis et al. 2011). Análises comparativas feitas por Assis et al. (2011) entre essas duas áreas, considerando o conjunto de descritores físico-químicos dos solos (saturação por bases, saturação por alumínio, capacidade de troca catiônica, potássio, fósforo, magnésio, soma de bases, $\mathrm{pH}$ em $\mathrm{CaCl}_{2}$ e percentagem de carbono), encontraram fortes diferenças entre FRS e FTB.

A área que compreende a FRS está situada na Praia da Fazenda, próximo à base do Núcleo Picinguaba, em cotas aproximadas de $10 \mathrm{~m}$ de altitude, estando sujeita à influência sazonal do lençol freático. A FTB localiza-se no sopé da Serra do Mar, cerca de $1 \mathrm{~km}$ além da localidade conhecida como Casa da Farinha, em cotas que variam de aproximadamente 40 a $80 \mathrm{~m}$ de altitude. Essas duas áreas distam cerca de $3 \mathrm{~km}$ entre si e, nessa faixa, uma importante rodovia (BR-101) corta o Parque Estadual da Serra do Mar.

\section{Delineamento amostral e análises numéricas}

\subsection{Amostragem e preparo das matrizes}

Delimitamos, em cada área (FRS e FTB), sete parcelas de $20 \times 20 \mathrm{~m}\left(400 \mathrm{~m}^{2}\right)$, totalizando 14 parcelas $(=0,56 \mathrm{ha})$, conforme a Figura 1. O sorteio das parcelas amostradas, dentre as 100 investigadas pelo BIOTA Gradiente Funcional em cada área (veja os outros artigos publicados nesta seção especial), foi feita por bootstrap (Smith \& van Belle 1984).

Nas parcelas todos os indivíduos de pteridófitas terrestres, rupícolas e epífitas com altura até 1,30 m no forófito foram amostrados e posteriormente identificados até o nível de espécie com a ajuda de chaves dicotômicas apropriadas para o grupo, comparações com material do Herbário SP e por meio do conhecimento de um dos autores deste trabalho. Classificamos as famílias segundo Smith et al. (2006). A nomenclatura dos binômios e de suas respectivas autoridades foi padronizada de acordo com Pichi Sermolli (1996).

$\mathrm{O}$ recenseamento das espécies que apresentavam crescimento vegetativo e formavam adensamentos populacionais (por rizomas subterrâneos longos e estolões, por exemplo) foi feito conforme Paciência \& Prado (2005a). A partir desses dados foram obtidas a composição florística e a abundância (número de indivíduos amostrados) das espécies.

Para as análises multivariadas (Análise de formação de grupos florísticos), geramos uma matriz de abundância das espécies nas parcelas, eliminando espécies que ocorreram em apenas uma parcela e que pouco acrescentam na análise dos dados. Para as análises de
Floresta de restinga

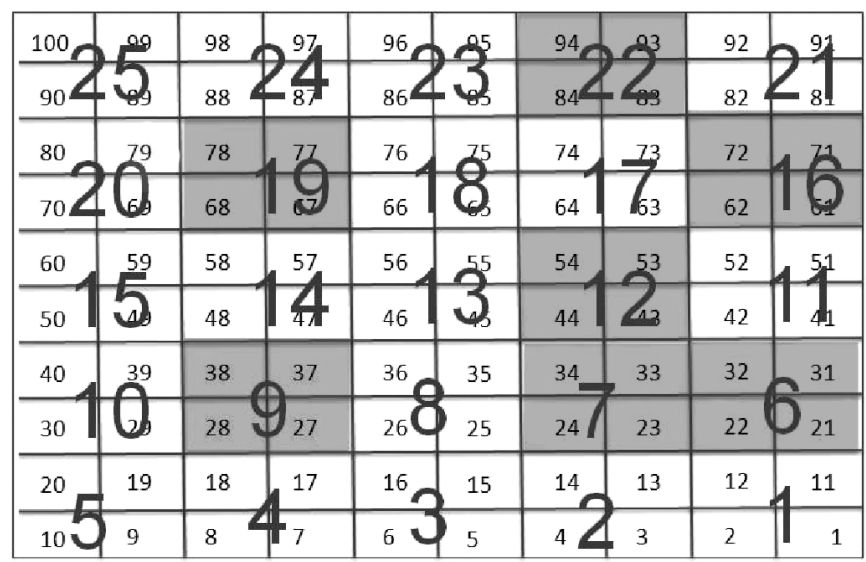

Floresta de terras baixas

\begin{tabular}{|l|l|l|l|l|l|l|l|l|l|}
\hline 100 & 00 & 98 & 97 & 96 & 85 & 94 & 93 & 92 & 91 \\
\hline 90 & 89 & 88 & 87 & 86 & 85 & 84 & 03 & 82 & 81 \\
\hline 80 & 79 & 78 & 77 & 76 & 75 & 74 & 73 & 72 & 71 \\
\hline 70 & 6 & 68 & 67 & 66 & 6 & 64 & 63 & 62 & 8 \\
\hline 60 & 59 & 58 & 57 & 56 & 55 & 54 & 53 & 52 & 51 \\
\hline 50 & 4 & 48 & 47 & 46 & 4 & 44 & 43 & 42 & 41 \\
\hline 40 & 39 & 38 & 37 & 36 & 35 & 34 & 33 & 32 & 31 \\
\hline 30 & 0 & 28 & 27 & 26 & 25 & 24 & 23 & 22 & 21 \\
\hline 20 & 19 & 18 & 17 & 16 & 15 & 14 & 13 & 12 & 11 \\
\hline 10 & 9 & 8 & 7 & 6 & 5 & 4 & 3 & 2 & 1 \\
\hline
\end{tabular}

Figura 1. Disposição das parcelas sorteadas (em cinza) de $20 \times 20 \mathrm{~m}$ para amostragem de duas comunidades de pteridófitas no Parque Estadual da Serra do Mar, em Ubatuba, SP, Brasil, dentre as 100 parcelas de $10 \times 10 \mathrm{~m}$ estudadas pelo BIOTA Gradiente Funcional.

Figure 1. Arrangement of $20 \times 20 \mathrm{~m}$ plots randomly selected (gray) used in the sampling of two communities of ferns in the Parque Estadual da Serra do Mar, Ubatuba, SP, Brazil, among the 100 plots $(10 \times 10 \mathrm{~m})$ studied by BIOTA Gradiente Funcional. 
diversidade, trabalhamos com uma segunda matriz, contendo todas as espécies.

\subsection{Análise de formação de grupos florísticos}

Objetivando verificar a ligação florística entre as amostras (parcelas), aplicamos três técnicas de análise multivariada: classificação hierárquica divisiva por TWINSPAN (Two-Way Indicator Species Analysis); (Hill et al. 1975); classificação hierárquica aglomerativa por UPGMA (Unweighted Pair-Groups Method using Arithmetic Averages); (Sneath \& Sokal 1973) usando o coeficiente de distância de Bray-Curtis; e, de forma complementar à UPGMA, procedemos à ordenação por PCO (Principal Coordinate Analysis, Análise de Coordenadas Principais); (explicada por Manly 1994 e por Jongman et al. 1995). O programa escolhido foi o FITOPAC 2.1 (Shepherd 2009).

Na TWINSPAN, adotamos 0-2-5-10-20 como níveis de corte para as pseudoespécies. O uso de pseudoespécies foi uma forma encontrada por Hill et al. (1975) para que a TWINSPAN, um método essencialmente qualitativo, pudesse processar uma matriz de dados quantitativos. Na UPGMA, calculamos o coeficiente de correlação cofenética, para que pudéssemos saber qual foi o grau de distorção do dendrograma em relação à matriz de similaridade original. Valores mais próximos de 1 indicam boa confiabilidade (baixa distorção). Processamos outros algoritmos (WPGMA, ligação completa, método de Ward, flexível-beta) com outros coeficientes (Morisita, distância corda, distância euclidiana simples) para verificarmos convergência nos resultados, o que aumentaria a confiabilidade para as discussões. $\mathrm{Na} \mathrm{PCO}$, comparamos os autovalores obtidos para os eixos de ordenação com a variância esperada pelo modelo broken stick de MacArthur (1957) no sentido de detectarmos até qual eixo a nossa análise seria justificável. Esse modelo foi criado a partir da hipótese de que o hiper-espaço dos nichos em uma comunidade poderia ser quebrado aleatoriamente, sem sobreposição de nichos (Martins \& Santos 1999), o que sugeriria que um importante fator ecológico estaria sendo compartilhado de maneira uniforme entre as espécies (Magurran 2004). Assim, autovalores em patamares superiores ao esperado pelo broken stick sugerem uma estrutura na variância dos dados que iria além da variância uniforme. Aqui também trabalhamos alternativamente com outros coeficientes combinados com a PCO (Morisita, distância corda, distância euclidiana simples) e outro método de ordenação (Correspondence Analysis; Análise de Correspondência) para detectarmos convergência ou não com os resultados obtidos inicialmente.

Padrões florísticos como os investigados neste trabalho podem ser influenciados pelo nível de agregação espacial dos indivíduos. Nesse sentido, calculamos o índice de agregação de Payandeh, que consiste na divisão da variância do número de plantas por parcela pela média do número de plantas por parcela (Payandeh 1970). Quando essa divisão resulta num valor inferior a 1,0, uma distribuição regular é sugerida; valores entre 1,0 e 1,5 sugerem distribuição aleatória e valores superiores a 1,5 indicam distribuição agregada (Durigan 2006).

\subsection{Análise de espécies indicadoras}

Utilizamos o método de Dufrêne \& Legendre (1997) para obtermos espécies indicadoras para as florestas de Restinga e de Terras Baixas. Esse método tem o mérito de combinar a abundância relativa com a frequência relativa das espécies e gerar um valor indicador que é máximo quando todos os indivíduos de uma espécie ocorrem num grupo (ex: grupo formado pelas parcelas da Restinga) e quando essa mesma espécie ocorre em todas as parcelas desse grupo. Outro ponto importante do método é que, mediante um processo de sucessivas aleatorizações, é gerado um valor-p (teste de Monte Carlo) para atestar a significância do valor indicador de cada espécie. O nível de significância foi definido como 5\%. Processamos essa análise no pacote PC-ORD, versão 4.0 (McCune \& Mefford 1999).

\subsection{Análises de diversidade}

As análises de diversidade consideraram as três modalidades de estimativa: riqueza, equabilidade e heterogeneidade (Krebs 1989, Martins \& Santos 1999, Magurran 2004). Riqueza é essencialmente o número de espécies numa dada área; equabilidade consiste na distribuição do número de indivíduos entre as diferentes espécies que a compõem; e heterogeneidade permite uma combinação entre riqueza e equabilidade num único índice. Porém, índices que são usados em estudos de diversidade (em qualquer das três modalidades) carecem de cuidado, pois as limitações no seu uso são grandes (Hurlbert 1971, Ludwig \& Reynolds 1988, Brewer \& Williamson 1994). Uma das maiores limitações refere-se ao fato de que diferentes índices podem levar a resultados distintos conforme a natureza dos dados (Hurlbert 1971). Embora Magurran (2004) argumente que não é desejável usar diversos índices, acreditamos que a convergência nos resultados de diferentes métodos seja útil para adicionar confiabilidade e ajudar a interpretar resultados que possam se mostrar intrigantes. Efetuamos todas essas análises no programa PAST versão 1.79 (Hammer et al. 2001). Comparamos os valores dos índices, entre FRS e FTB, por meio de IC $95 \%$ gerados a partir das médias originadas por bootstrap (Smith \& van Belle 1984), exceto para o índice de concentração de Simpson, que foi apresentado em seu valor absoluto.

$\mathrm{Na}$ análise de riqueza de espécies, consideramos que eventuais diferenças podem se dar simplesmente porque uma área possui maior número de indivíduos do que outra - uma área com maior número de indivíduos possui chance maior de abrigar maior número de espécies. Para eliminarmos esse artifício, procedemos a uma rarefação por indivíduos (proposto por Sanders 1968 e reapresentado por Krebs 1989) e comparamos a riqueza entre as duas comunidades por meio de uma curva de acumulação de espécies plotada contra o número de indivíduos. Essa curva, gerada por aleatorização, foi utilizada também para verificarmos a suficiência amostral. Por considerarmos esse método suficientemente seguro e um dos mais adequados para estimativa de riqueza, resolvemos não proceder a outros.

Para estimarmos a equabilidade calculamos o índice de concentração de Simpson (Magurran 2004) para cada área, considerado por Martins \& Santos (1999) o melhor para essa finalidade. Checamos a convergência do resultado produzido por esse índice com outros índices de equabilidade (Buzas \& Gibson $=\mathrm{e}^{\mathrm{H}} / \mathrm{S}$, Berger-Parker $=\mathrm{d}$ e Pielou $=\mathrm{J}$ '; Magurran 2004).

Por fim, trabalhamos com a modalidade "heterogeneidade", calculando o índice de diversidade específica de Simpson complementar (1-D) (Simpson 1949, Magurran 2004) para cada área. O índice de Simpson é, para Magurran (2004), um dos mais robustos; porém, como ele enfatiza a dominância em detrimento da riqueza de espécies, optamos por também proceder ao cálculo e à comparação do índice de Shannon (H'), pois este, em relação ao primeiro, tende a enfatizar mais a riqueza (Magurran 2004). Disso decorre que uma comunidade que apresente maior riqueza tende a apresentar maior H', exceto se sua equabilidade for extremamente baixa em comparação com a outra área. Porém, se a comunidade apresentar maior riqueza, maior H' e também maior valor no índice de Simpson complementar (1-D), então a indicação de que ela é de fato a mais diversa será muito mais forte.

\section{Resultados}

Nas duas áreas amostramos 3.482 indivíduos, dos quais 1.366 ocorreram na Floresta de Restinga (FRS) e 2.116 na Floresta de Terras Baixas (FTB). Os indivíduos contabilizados pertencem a 
15 famílias, 25 gêneros e 40 espécies (Tabela 1). Destas espécies, 14 foram encontradas na FRS, 29 na FTB e 5 foram encontradas nas duas áreas (Tabela 1).

\section{Grupos florísticos}

A análise TWINSPAN, no primeiro nível de divisão (autovalor $=\lambda$ de 0,771 ), indicou a formação de dois grandes grupos: o grupo 1 correspondeu a todas as parcelas encontradas na FRS e o grupo 2, a todas as da FTB. As divisões seguintes tiveram autovalores consideravelmente inferiores ao da primeira divisão $(\lambda=0,245$ na segunda divisão, que separou parcelas da FTB, e $\lambda=0,250$ na terceira, que separou parcelas da FRS). As demais divisões falharam, em razão do baixo número de amostras disponíveis.

O dendrograma gerado pela UPGMA assemelhou-se bastante ao resultado obtido pela TWINSPAN, apontando para a formação de dois grupos distintos, FRS e FTB (Figura 2), como esperávamos. A correlação cofenética foi de 0,947 , indicando que $94,7 \%$ das informações de similaridade foram reproduzidas fielmente no dendrograma, o que significa uma baixa distorção entre a matriz calculada para formação do dendrograma e a matriz original. Na FRS,

Tabela 1. Lista das espécies amostradas nas áreas de FRS (Floresta de Restinga) e FTB (Floresta de Terras Baixas) no Parque Estadual da Serra do Mar, em Ubatuba, SP, Brasil.

Table 1. Check-list of species sampled in the areas FRS (Restinga Forest) and FTB (Lowland Forest) in the Parque Estadual da Serra do Mar, Ubatuba, SP, Brazil

\begin{tabular}{|c|c|c|c|}
\hline Famílias & Espécies & FRS & FTB \\
\hline Anemiaceae & Anemia mandioccana Raddi & $\mathrm{X}$ & $\mathrm{X}$ \\
\hline \multirow[t]{2}{*}{ Aspleniaceae } & Asplenium mucronatum C. Presl & - & $\mathrm{X}$ \\
\hline & Asplenium pteropus Mett. & - & $\mathrm{X}$ \\
\hline \multirow[t]{4}{*}{ Cyatheaceae } & Alsophila setosa (Kaulf.) Domin & - & $\mathrm{X}$ \\
\hline & Cyathea atrovirens (Langsd. \& Fisch.) Domin & $\mathrm{X}$ & - \\
\hline & Cyathea delgadii Sternb. & - & $\mathrm{X}$ \\
\hline & Cyathea phalerata Mart. & - & $\mathrm{X}$ \\
\hline \multirow[t]{6}{*}{ Dryopteridaceae } & Bolbitis serratifolium (Mert. ex Kaulf.) Schott & - & $\mathrm{X}$ \\
\hline & Ctenitis deflexa (Kaulf.) Copel. & $\mathrm{X}$ & $\mathrm{X}$ \\
\hline & Lomagramma guianensis (Aubl.) Ching & - & $\mathrm{X}$ \\
\hline & Olfersia cervina (L.) Kunze & - & $\mathrm{X}$ \\
\hline & Polybotrya cylindrica Kaulf. & $\mathrm{X}$ & $\mathrm{X}$ \\
\hline & Stigmatopteris caudata (Raddi) C. Chr. & - & $\mathrm{X}$ \\
\hline \multirow[t]{4}{*}{ Hymenophyllaceae } & Abrotictyum rigidum $(\mathrm{Sw})$. & - & $\mathrm{X}$ \\
\hline & Didymoglossum kraussi (Hook. \& Grev.) C. Presl & - & $\mathrm{X}$ \\
\hline & Trichomanes cristatum Kaulf. & $X$ & - \\
\hline & Vandenboschia radicans (Sw.) Copel & - & $\mathrm{X}$ \\
\hline \multirow[t]{2}{*}{ Lindsaeaceae } & Lindsaea lancea (L.) Bedd & $\mathrm{X}$ & - \\
\hline & Lindsaea quadrangularis Raddi & $\mathrm{X}$ & - \\
\hline \multirow[t]{5}{*}{ Lomariopsidaceae } & Elaphoglossum lingua (C. Presl) Brack. & $\mathrm{X}$ & - \\
\hline & Elaphoglossum macahense (Fée) Rosenst. & $\mathrm{X}$ & - \\
\hline & Elaphoglossum macrophyllum (Mett. ex Kuhn) H. Christ & $\mathrm{X}$ & - \\
\hline & Nephrolepis cordifolia (L.) C. Presl & - & $\mathrm{X}$ \\
\hline & Nephrolepis rivularis (Vahl) Ching & - & $\mathrm{X}$ \\
\hline Marattiaceae & Dannaea geniculata Raddi & - & $\mathrm{X}$ \\
\hline \multirow[t]{7}{*}{ Polypodiaceae } & Campyloneurum decurrens C. Presl & - & $\mathrm{X}$ \\
\hline & Campyloneurum major (Hieron. ex Hicken) Lellinger & $\mathrm{X}$ & $\mathrm{X}$ \\
\hline & Campyloneurum repens (Aubl.) C. Presl & - & $\mathrm{X}$ \\
\hline & Microgramma geminata Presl & $\mathrm{X}$ & $\mathrm{X}$ \\
\hline & Microgamma tecta (Kaulf.) Alston & - & $\mathrm{X}$ \\
\hline & Microgramma vacciniifolia (Langsd. \& Fisch.) Copel. & $\mathrm{X}$ & - \\
\hline & Pecluma chnoophora (Kunze) & - & $\mathrm{X}$ \\
\hline Pteridaceae & Adiantum windischii J. Prado & - & $\mathrm{X}$ \\
\hline Saccolomataceae & Saccoloma inaequale (Kunze) Mett. & - & $\mathrm{X}$ \\
\hline Selaginellaceae & Selaginella sulcata (Desv. ex Poir.) Spring ex Mart. & - & $\mathrm{X}$ \\
\hline \multirow[t]{3}{*}{ Thelypteridaceae } & Macrothelypteris torresiana (Gaudich) Ching & - & $\mathrm{X}$ \\
\hline & Thelypteris angustifolia (Willd.) Proctor & - & $\mathrm{X}$ \\
\hline & Thelypteris longifolia (Desv.) R. M. Tryon & $\mathrm{X}$ & - \\
\hline Vittariaceae & Radiovittaria stipitata Kunze & $\mathrm{X}$ & - \\
\hline Woodsiaceae & Diplazium cristatum (Desr.) Alston & - & $\mathrm{X}$ \\
\hline
\end{tabular}


os dois grupos maiores fundiram-se a aproximadamente 0,75 na escala de Bray-Curtis. Três espécies do subgrupo formado pelas parcelas A6, A7 e A9 (Trichomanes cristatum, Elaphoglossum macrophyllum e Elaphoglossum macahense) apresentaram grande abundância; essas mesmas espécies estiveram representadas por poucos indivíduos nas outras parcelas. O outro subgrupo (A12, A16, A19 e A22) conteve as espécies mais comuns da área e que ocorreram na maioria das parcelas da FRS. A parcela A12 ficou um pouco dissociada neste segundo subgrupo, provavelmente por ser a única onde foram registradas as espécies Thelypteris longifolia e Cyathea atrovirens. O grupo da FTB mostrou maior similaridade interna: a distância máxima de Bray-Curtis que separou parcelas dessa área foi de 0,45. A formação do subgrupo contendo as parcelas B11 e B12 provavelmente deveu-se à ocorrência de Campyloneurum major, que está presente apenas nestas parcelas. O outro subgrupo (parcelas B2, B3, B14, B22 e B25) apresenta as espécies mais comuns na FTB e a diferença entre as parcelas é muito sutil. Os outros métodos processados nas análises prévias revelaram essencialmente o mesmo padrão, exceto quando a UPGMA foi combinada com a distância euclidiana simples (não apresentado), que agrupou inicialmente três parcelas da FRS (A6, A7 e A9) em contraposição a todas as demais, o que provavelmente se deve à já ressaltada abundância diferencial de T. cristatum, E. macrophyllum e E. macahense.

A análise PCO (Figura 3) efetuada com o coeficiente de Bray-Curtis mostrou elevada segregação entre as parcelas das áreas FRS e FTB no primeiro eixo de ordenação $(\lambda=2,074)$, o qual explicou mais de $56 \%$ da variância total dos dados. O segundo eixo $(\lambda=0,865$, representando quase $25 \%$ da variância total) revelou uma separação da FRS em dois blocos, um do lado positivo e outro do lado negativo. Nesse mesmo eixo, a FTB mostrou uma disposição homogênea, concentrada próximo ao escore zero - apenas a parcela B12 posicionou-se de forma mais isolada. A explicação da variância total dada por cada um desses eixos superou a explicação esperada pelo modelo broken stick, que foi de $24,46 \%$ e de $16,77 \%$, respectivamente. O terceiro eixo explicou menos de $10 \%$ da variância total e esse valor foi abaixo do esperado pelo broken stick (12,92\%), não sendo, portanto, considerado significativo. Quando a mesma PCO foi combinada com a distância euclidiana simples (não apresentada), também houve segregação entre as duas florestas, mas a FTB já não mostrou o padrão homogêneo verificado anteriormente, sendo indicada a formação de um gradiente entre as parcelas dessa área. A CA (não mostrada) indicou resultados muito semelhantes aos encontrados para a PCO com distância de Bray-Curtis.

Quanto ao nível de agregação dos indivíduos, a FRS apresentou aproximadamente $79 \%$ de suas espécies com distribuição agregada (Agregação de Payandeh, P > 1,5), 14\% com distribuição regular $(\mathrm{P}<1,0)$ e $7 \%$ com distribuição aleatória $(1,0<\mathrm{P}<1,5)$ (Tabela 2$)$. Na FTB, cerca de $72 \%$ das espécies mostraram-se agregadas, $21 \%$ aleatórias e $7 \%$ regulares (Tabela 2). Essa distribuição mais aleatória das espécies da FTB em relação às da FRS pode ter influenciado a formação de um gradiente detectado na FTB pela PCO + distância euclidiana simples.

\section{Espécies indicadoras}

O método de Dufrêne \& Legendre (1997) revelou a existência das seguintes espécies indicadoras para a FRS: Elaphoglossum macrophyllum, Lindsaea lancea, Lindsaea quadrangularis e Trichomanes cristatum. Destas, L. lancea foi a única que apresentou Valor Indicador (VI) máximo (100), ou seja, essa espécie ocorreu em todas as parcelas da FRS e nenhum de seus indivíduos ocorreu na FTB. Para a FTB, as seguintes espécies foram consideradas indicadoras: Asplenium mucronatum, Bolbitis serratifolium, Campyloneurum repens, Ctenitis deflexa, Lomagramma guianensis, Olfersia cervina, Polybotrya cylindrica e

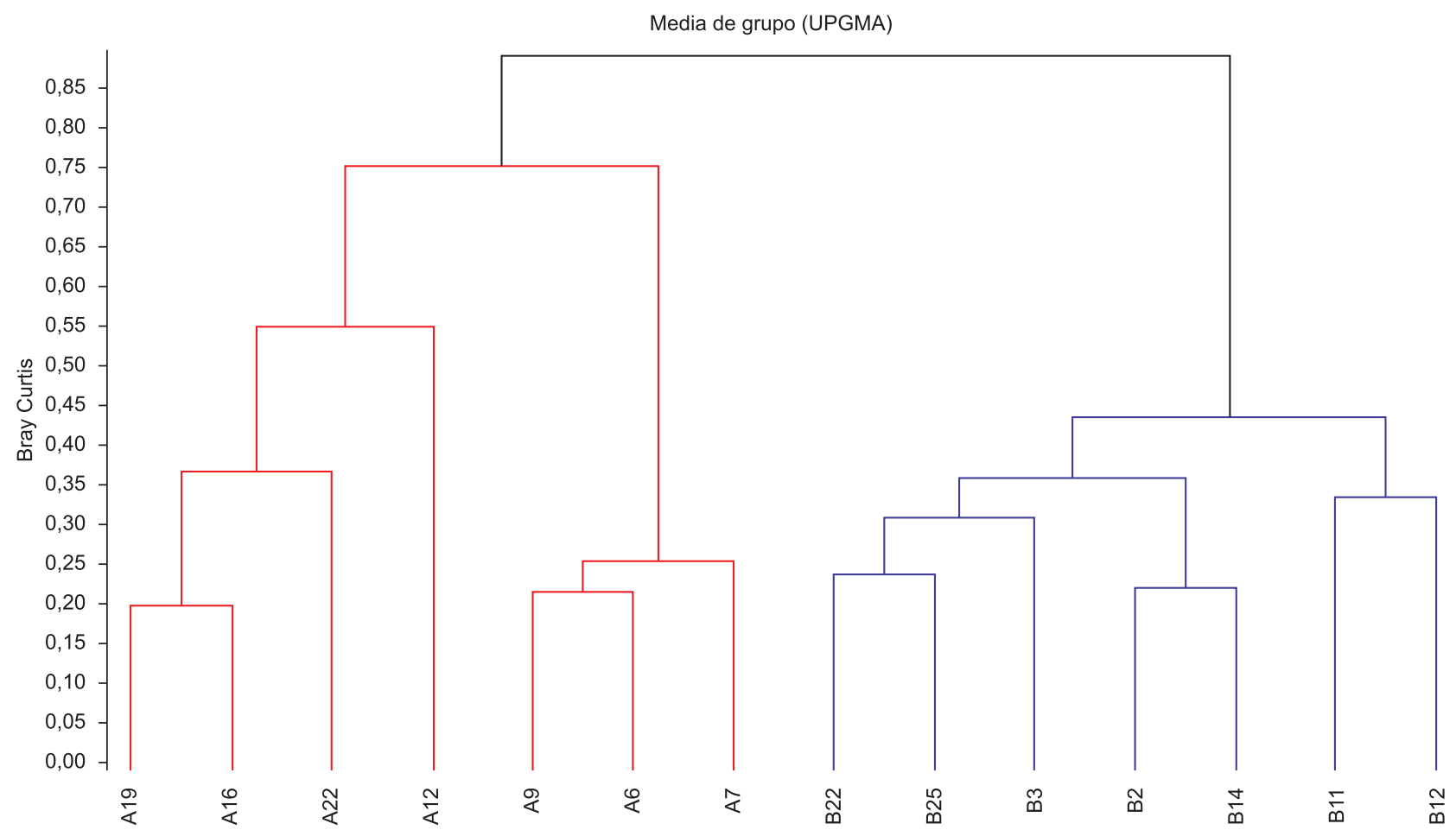

Figura 2. Dendrograma obtido por UPGMA, calculado pelo coeficiente de distância de Bray-curtis, resultante de uma matriz de abundância para duas comunidades de pteridófitas amostradas no Parque Estadual da Serra do Mar, em Ubatuba, SP, Brasil. A: parcelas da FRS; B: parcelas da FTB.

Figure 2. Dendrogram obtained by UPGMA, calculated by the Bray-Curtis distance coefficient, resulting from an abundance matrix for two communities of ferns sampled in the Parque Estadual da Serra do Mar, Ubatuba, SP, Brazil. A: plots of FRS; B: plots of FTB. 
Vandenboschia radicans. As espécies com VI máximo (100) foram Campyloneurum repens e Vandenboschia radicans.

\section{Diversidade}

As curvas resultantes da rarefação por indivíduos indicaram forte diferença de riqueza específica entre as duas comunidades (Figura 4). No ponto de igual esforço amostral (linha tracejada), a FRS apresentou uma riqueza de 13,99 espécies (IC 95\%: \pm 0,21), enquanto a FTB apresentou 26,71 espécies (IC 95\%: $\pm 2,46$ ). Na FRS, houve estabilização completa da curva; na FTB, houve tendência a essa estabilização, sendo possível prever um pequeno incremento de espécies caso mais indivíduos fossem amostrados. De modo geral, portanto, o esforço amostral (número de indivíduos amostrados) mostrou-se suficiente para se avaliar a riqueza das duas áreas.

Também houve diferenças quanto à equabilidade pelo índice de concentração de Simpson $\left(\mathrm{E}_{1 / \mathrm{D}}\right)$, mas o padrão de distribuição de abundância foi mais equitativo na FRS do que na FTB (Tabela 3). Outros índices de equabilidade (Buzas \& Gibson = $\mathrm{e}^{\mathrm{H}} / \mathrm{S}$, Berger-Parker $=\mathrm{d}$ e Pielou $=\mathrm{J}$ ') também indicaram que a FRS é mais equitativa que a FTB (Tabela 3 ). Alguns dados poderiam justificar esse resultado. Das 14 espécies amostradas na FRS, a que apresentou maior abundância relativa foi Trichomanes cristatum $(29,14 \%)$. Essa espécie e outras quatro (Elaphoglossum macahense, Campyloneurum major, Lindsaea quadrangularis e Polybotrya cylindrica) detiveram pouco mais de $90 \%$ da abundância total dessa comunidade. Isso implica no fato de que cerca de $35 \%$ das espécies foram responsáveis pela quase totalidade dos indivíduos amostrados. Das 29 espécies encontradas na FTB, Campyloneuron repens respondeu por 34,07\% do total de indivíduos. Esta e mais seis espécies (Vandenboschia radicans, Campyloneurum major, Polybotrya cylindrica, Bolbitis serratifolium, Olfersia cervina e Stigmatopteris caudata) apresentaram pouco mais de $90 \%$ da abundância total dessa comunidade. Isso significa que menos de $25 \%$ das espécies foram responsáveis pela quase totalidade dos indivíduos amostrados. $\mathrm{Na}$ FRS, a espécie Vittaria stipitata foi considerada rara, com apenas um indivíduo amostrado; na FTB, cinco espécies foram incluídas nessa categoria: Asplenium pteropus, Cyathea delgadii, Cyathea phalerata, Diplazium cristatum e Thelypteris angustifolia.

Por fim, o índice de diversidade de Simpson complementar (1-D), que tende a conferir maior peso para a dominância em relação à riqueza (Magurran 2004), não evidenciou diferenças entre a FRS $(1-\mathrm{D}=0,7950)$ e a FTB $(1-\mathrm{D}=0,8064)$, com sobreposição entre o IC inferior da FTB e o IC superior da FRS (Tabela 3). Por outro lado, a não sobreposição de IC 95\% no índice de Shannon (H'), o qual tende a conferir maior peso para riqueza (Magurran 2004), indicou que a FTB seria uma área mais diversa do que a FRS (Tabela 3).

\section{Discussão}

\section{Grupos florísticos}

Um grupo de espécies vegetais crescendo juntas em um determinado local, mostrando uma afinidade entre si, constitui uma comunidade vegetal (Kent \& Coker 1992). Essa afinidade pode ser determinada pelo fato dessas espécies terem requerimentos similares em relação a fatores como luz, temperatura, água, drenagem e nutrientes dos solos, e possivelmente por compartilharem habilidades de tolerar interferências (Kent \& Coker 1992). Nesse sentido, as duas áreas analisadas parecem formar comunidades distintas, possivelmente influenciadas pelos solos (mais férteis na Floresta de Terras Baixas-FTB e mais restritivos na Floresta de Restinga-FRS; Assis et al. 2011), pela presença de um curso d'água (ao qual as plantas da FRS estão sujeitas) e de uma estrada que corta o Parque e separa as duas áreas. Esses fatores poderiam atuar como filtros ambientais, dificultando o estabelecimento de espécies originadas de outras comunidades (Ackerly 2003). Como Assis et al. (2011) também encontraram separação consistente para o componente arbóreo, fica claro que a vegetação, de modo geral, tem respondido a essas diferenças nos dois ambientes.

Os fatores que influenciam ou determinam a composição florística de uma comunidade podem ser resumidos em duas grandes correntes

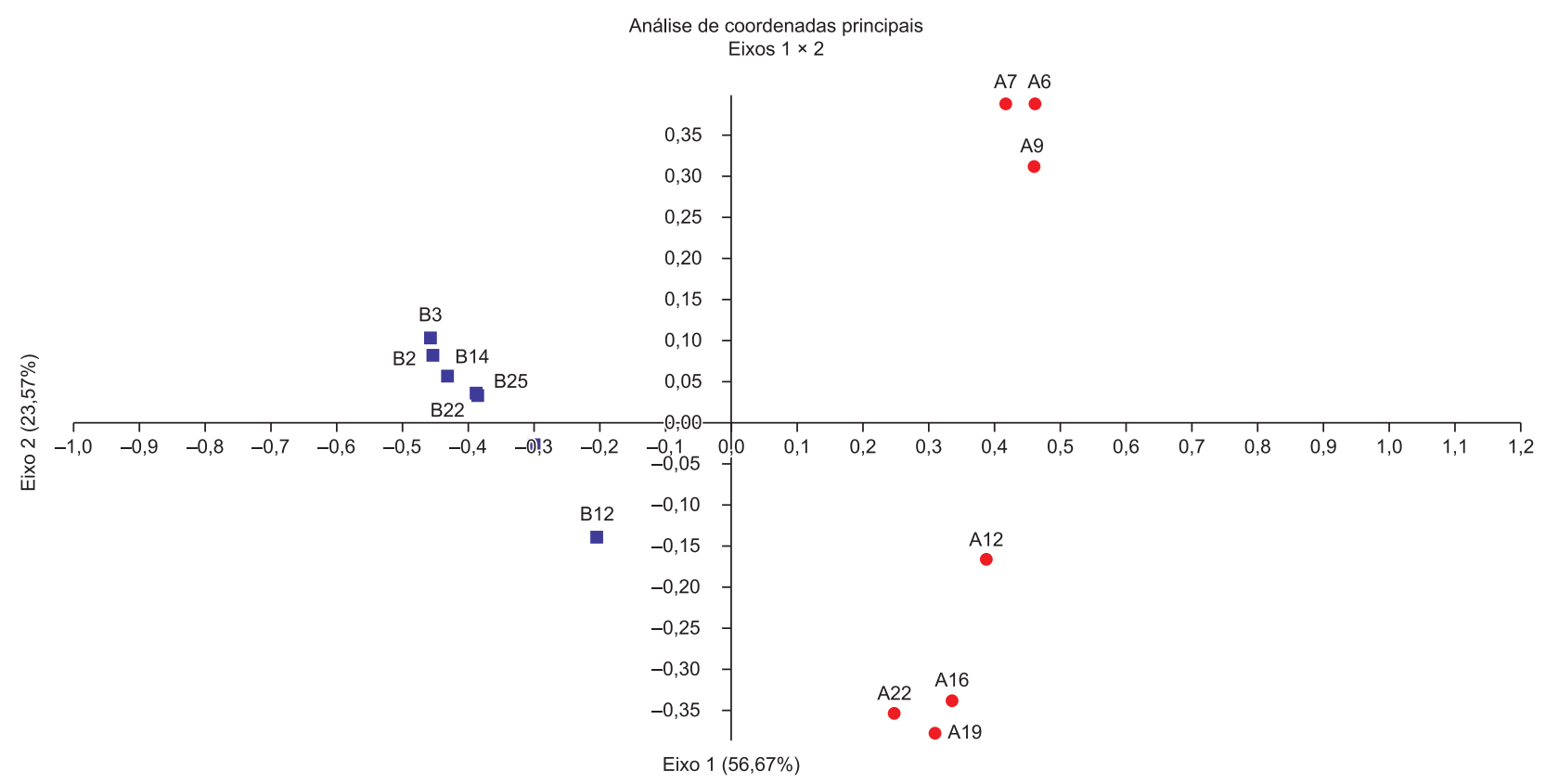

Figura 3. Análise de ordenação PCO combinada com coeficiente de distância de Bray-Curtis, resultante de uma matriz de abundância para duas comunidades de pteridófitas amostradas no Parque Estadual da Serra do Mar, em Ubatuba, SP, Brasil. A: parcelas da FRS; B: parcelas da FTB.

Figure 3. PCO analysis combined with Bray-Curtis distance coefficient, resulting from an abundance matrix for two communities of ferns sampled in the Parque Estadual da Serra do Mar, Ubatuba, SP, Brazil. A: plots of FRS; B: plots of FTB. 
(Hubbell 2001, Jones et al. 2006): a da "comunidade baseada na dispersão" (dispersal assembly) e a da "comunidade baseada no nicho" (niche assembly). No primeiro caso, a composição seria essencialmente relacionada às taxas de imigração de suas espécies constituintes, tendendo a apresentar menor similaridade entre áreas com o aumento da distância geográfica que as separa (Hubbell 2001, Jones et al. 2006), uma vez que eventos estocásticos teriam papel essencial no estabelecimento dos padrões florísticos (Hubbell 2001). Se assumíssemos essa concepção como explicação para os nossos resultados, as diferenças ambientais entre a FRS e a FTB teriam reduzida importância na forte dissimilaridade encontrada, pois as espécies constituintes das duas áreas seriam ecologicamente equivalentes. A explicação, então, não poderia ser a de que diferentes propriedades dos solos determinariam a disjunção florística. Porém, Jones et al. (2006) ressaltam que, ao menos para os estudos realizados sobre as pteridófitas na Amazônia, o modelo de comunidade baseada no nicho teria maior poder preditivo em relação ao modelo de comunidade baseada na dispersão. As características ambientais da FRS diferem largamente em relação às da FTB, e a distribuição e a composição das espécies parecem ser uma consequência dessa disparidade. As variações nas propriedades físico-químicas e de textura dos solos, a influência do curso d'água sobre a FRS e o rompimento brusco do Parque Estadual da Serra do Mar pela estrada poderiam determinar uma consistente segregação florística influenciada ou determinada pela ocupação diferencial de nichos.

A influência dos cursos d'água poderia ajudar a explicar essas diferenças: por um lado, o próprio sistema reprodutivo dessas plantas apresenta dependência da água, mas em contrapartida, muitas espécies possuem algum nível de especialização edáfica (Tuomisto \& Poulsen 1996), sendo capazes de resistir ou tolerar a seca. Com isso, algumas espécies teriam maior capacidade para sobreviver e se reproduzir na FRS, enquanto outras estariam adaptadas ao ambiente da FTB. Isso, porém, explicaria apenas uma parte da distinção florística entre os dois ambientes, uma vez que, seguindo esse raciocínio, as espécies da FRS teriam capacidade de sobreviver aos dois ambientes. Outros fatores, então, precisam ser invocados para que tentemos explicar de forma mais contundente esses resultados. Podemos considerar que a similaridade florística e o padrão de distribuição espacial possuem ligações estreitas, uma vez que, em conjunto, determinam os padrões florísticos de uma localidade. O padrão espacial proporcionalmente mais agregado na Floresta de Restinga (FRS) sugere a existência de uma maior heterogeneidade espacial nas taxas de suprimento de recursos nesse ambiente. Essa relação se justifica se considerarmos que a heterogeneidade tende a levar a uma distribuição preferencial das espécies, as quais procuram sítios favoráveis para sobreviver e se reproduzir. Nessa área, os fatores que podem ser responsáveis pela distribuição espacial das espécies são aqueles já bem documentados na literatura, como as características do substrato (Tuomisto et al. 2002, 2003), muito mais arenoso que o da FTB (Assis et al. 2011), e a topografia (Poulsen \& Nielsen 1995), pois a FRS está situada numa planície litorânea sem matacões (blocos de rocha maciços e arredondados), muito diferente da FTB. Além disso, o histórico, a localização e o grau de fragmentação das áreas estudadas também são fatores a serem considerados ao analisar a distribuição das espécies (Paciência \& Prado 2004, 2005a,b, Faria et al. 2009). A BR-101 que atravessa o Parque na região situada entre a restinga e as terras baixas

Tabela 2. Espécies com distribuição agregada, regular e aleatória em duas comunidades de pteridófitas amostradas no Parque Estadual da Serra do Mar, em Ubatuba, SP, Brasil.

Table 2. Species with patchy, regular and randomic distribution in two communities of ferns sampled in the Parque Estadual da Serra do Mar, Ubatuba, SP, Brazil.

\begin{tabular}{|c|c|c|c|}
\hline Área & Espécies com distribuição agregada & $\begin{array}{c}\text { Espécies com } \\
\text { distribuição } \\
\text { regular }\end{array}$ & $\begin{array}{l}\text { Espécies com } \\
\text { distribuição } \\
\text { aleatória }\end{array}$ \\
\hline $\begin{array}{l}\text { Floresta } \\
\text { de } \\
\text { Restinga }\end{array}$ & $\begin{array}{l}\text { Anemia mandioccana Campyloneurum major Elaphoglossum lingua Elaphoglossum } \\
\text { macrophyllum Elaphoglossum macahense Lindsaea lanceae } \\
\text { Lindsaea quadrangularis } \\
\text { Microgramma vacciniifolia } \\
\text { Polybotrya cylindrica } \\
\text { Thelypteris longifolia } \\
\text { Trichomanes cristatum }\end{array}$ & $\begin{array}{l}\text { Cyathea } \\
\text { atrovirens } \\
\text { Microgramma } \\
\text { geminata }\end{array}$ & $\begin{array}{l}\text { Radioviittaria } \\
\text { stipitata }\end{array}$ \\
\hline $\begin{array}{l}\text { Floresta } \\
\text { de } \\
\text { Terras } \\
\text { Baixas }\end{array}$ & $\begin{array}{l}\text { Abrodictyum rigidum } \\
\text { Adiantum windischii } \\
\text { Alsophylla setosa } \\
\text { Asplenium mucronatum } \\
\text { Bolbitis serratifolium } \\
\text { Campyloneurum decurrens } \\
\text { Campyloneurum major } \\
\text { Campyloneurum repens } \\
\text { Ctenitis deflexa } \\
\text { Didymoglossum kraussi Lomagramma guianensis } \\
\text { Macrothelypteris torresiana } \\
\text { Microgramma geminata } \\
\text { Nephrolepis cordifolia } \\
\text { Nephrolepis rivularis } \\
\text { Olfersia cervina } \\
\text { Polybotrya cylindrica } \\
\text { Saccoloma inaequale } \\
\text { Selaginella sulcata } \\
\text { Stigmatopteris caudata } \\
\text { Vandenboschia radicans }\end{array}$ & $\begin{array}{l}\text { Microgramma } \\
\text { tecta } \\
\text { Pecluma } \\
\text { chnoophora }\end{array}$ & $\begin{array}{l}\text { Asplenium pteropus } \\
\text { Cyathea delgadii } \\
\text { Cyathea phalerata } \\
\text { Diplazium } \\
\text { cristatum } \\
\text { Thelypteris } \\
\text { angustifolia }\end{array}$ \\
\hline
\end{tabular}


constitui uma perturbação com possíveis influências na distribuição das espécies ao longo das últimas décadas. Sugerimos que um balanço de todos esses fatores resultaria em fortes diferenças florísticas, como verificamos nas análises de agrupamento e ordenação.

\section{Espécies indicadoras}

Lindsaea lancea, a espécie com maior valor indicador na Floresta de Restinga (FRS), é muito comum e bem distribuída nas Américas (Moran 1995). Pode ser encontrada desde o nível do mar até $1.500 \mathrm{~m}$ de altitude, crescendo em florestas úmidas perto de moitas e bainhas de palmeiras, em áreas alagadas sobre solos arenosos, como na área estudada, ou em solos argilosos. Em áreas rochosas, ocorrem principalmente sobre troncos de árvores ou toras caídas (Cremers \& Kramer 1991). Trichomanes cristatum, que possui maior abundância relativa na área, sendo também uma espécie indicadora da FRS, é amplamente distribuída na América do Sul e pode ser encontrada como terrestre e às vezes como epífita, desde o nível do mar até $1.400 \mathrm{~m}$ de altitude (embora seja menos frequente acima de $1.000 \mathrm{~m}$ ); cresce em florestas úmidas, locais sujeitos à inundação e ambientes paludosos (Windisch 1990, 1992). Essa espécie foi registrada com

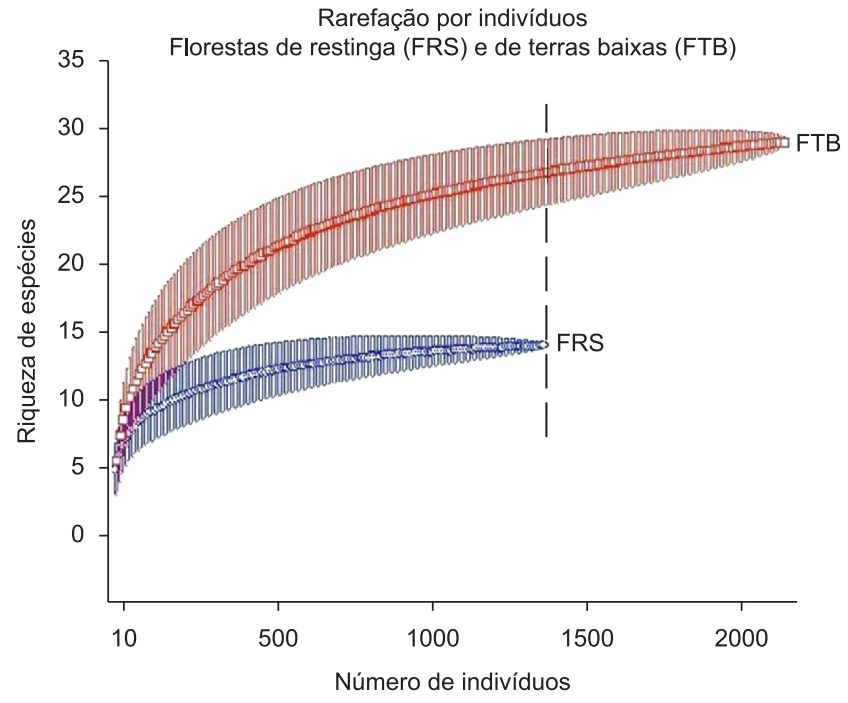

Figura 4. Curvas de acumulação de espécies usando o método de rarefação por indivíduos, para duas comunidades de pteridófitas amostradas no Parque Estadual da Serra do Mar, em Ubatuba, SP, Brasil.

Figure 4. Curves of species accumulation using the individual-based rarefaction method for two communities of ferns sampled in the Parque Estadual da Serra do Mar, Ubatuba, SP, Brazil. grande ocorrência (abundância) em uma restinga da costa do Paraná (Paciência 2008), o que pode refletir sua preferência por áreas periodicamente inundadas. As duas espécies (L. lancea e T. cristatum) foram encontradas também em áreas com influência aluvial, como no interior do Estado de São Paulo (Nóbrega \& Prado 2008). Isto sugere que a presença do Rio da Fazenda no local pode contribuir para a ocorrência e sucesso destas espécies.

Já na FTB, Campyloneurum repens e Vandenboschia radicans, espécies com maior valor indicador, são amplamente distribuídas nas florestas úmidas do sul e sudeste do Brasil (León 1995, Pacheco 1995), também podendo ser encontradas na Amazônia Central, onde são relativamente raras (Zunquim et al. 2008) e crescem principalmente como epífitas no sub-bosque das florestas. $\mathrm{Na}$ área estudada estas espécies também são preferencialmente epífitas e ocorrem em baixas alturas, preferencialmente até $1 \mathrm{~m}$ no forófito.

Ressaltamos que as espécies indicadoras para os ambientes investigados não são, necessariamente, as espécies indicadoras da restinga ou do sopé da encosta para o conjunto da Serra do Mar. Somente poderíamos afirmar isso se tivéssemos incluído todos os grupos florísticos possíveis para esse conjunto. Assim, para os dados disponíveis e exclusivamente para a região mais baixa da Serra do Mar em Ubatuba, tais espécies foram tidas como indicadoras de cada ambiente (restinga e terras baixas). Outra ressalva importante é que apenas uma espécie na restinga (Lindsaea lancea) e duas nas terras baixas (Campyloneurum repens e Vandenboschia radicans) foram indicadoras perfeitas (valor indicador $=100$ ), tendo ocorrido em todas as parcelas de seu grupo e em nenhuma do outro grupo.

\section{Diversidade}

Conforme ressaltamos, o padrão espacial da Floresta de Restinga (FRS) sugere que haja, ali, maior heterogeneidade ambiental. Numa comunidade, existem espécies que atingem mais rapidamente o ponto a partir do qual o balanço entre crescimento dependente de recursos e perdas com herbivorias e mortalidade torna-se favorável ao crescimento (Tilman 1982); essas espécies, em ambientes com recursos limitados e heterogeneamente distribuídos no espaço (como supomos ser o caso da FRS), eliminariam as demais (Tilman \& Pacala 1993).

Assis et al. (2011) propuseram algumas explicações para a maior riqueza de espécies arbóreas na Floresta de Terras Baixas (FTB) em relação à FRS. Segundo esses autores, a maior fertilidade na FTB e a maior saturação de alumínio na FRS são fatores essenciais que atuariam na seletividade de espécies nessas duas áreas. Assim, a maior riqueza de espécies encontrada na FTB pode ser um reflexo da partição de nichos (Begon et al. 2007) condicionada pelas variáveis ambientais. Considerando que não existe uma significativa variação

Tabela 3. Índices de equabilidade e heterogeneidade utilizada na análise de duas comunidades de pteridófitas amostradas no Parque Estadual da Serra do Mar, em Ubatuba, SP, Brasil. Valores em negrito referem-se às médias.

Table 3. Evenness and heterogeneity indices for two communities of ferns sampled in the Parque Estadual da Serra do Mar, Ubatuba, SP, Brazil. Values in bold refer to the averages.

\begin{tabular}{lll}
\hline \multicolumn{1}{c}{ Índice } & \multicolumn{1}{c}{ Floresta de Restinga } & Floresta de Terras Baixas \\
\hline Equabilidade & \multicolumn{1}{c}{0,3946} & 0,3609 \\
Simpson $\left(\mathrm{E}_{1 / \mathrm{D}}\right)$ & 0,4084 (IC inf) $-0,4239-0,4981$ (IC sup) & 0,2592 (IC inf) $-0.2625-0,3138$ (IC sup) \\
Buzas \& Gibson (e $\mathrm{H} / \mathrm{S})$ & 0,2672 (IC inf) $-0,2914-0,3148$ (IC sup) & 0,3209 (IC inf) $-0,3407-0,3601$ (IC sup) \\
Berger-Parker (d)* & 0,6607 (IC inf) $-0,6748-0,7187$ (IC sup) & 0,5963 (IC inf) $-0,6028-0,6368$ (IC sup) \\
Pielou (J') & & \\
Heterogeneidade & 0,7844 (IC inf) $-0,7950-0,8029$ (IC sup) & 0,7954 (IC inf) $-0,8064-0,8159$ (IC sup) \\
Simpson (1-D) & 1,7240 (IC inf) $-1,7810-1,8180$ (IC sup) & 1,9720 (IC inf) $-2,0300-2,073$ (IC sup) \\
Shannon (H') &
\end{tabular}

*A interpretação desse índice é inversa: quanto mais próximo o seu valor for de 1,0, menor é a equabilidade. 
de altitude entre as duas áreas, as diferenças encontradas podem estar relacionadas às características físico-químicas do solo e à dinâmica da água. Esses fatores, aliados à maior proximidade do mar, portanto a uma maior exposição ao sal carreado pelo vento, podem estar associadas à menor riqueza encontrada na FRS.

Um resultado intrigante e que necessitaria um estudo complementar foi a maior equabilidade na FRS, uma vez que é raro encontrarmos, numa comparação entre dois ou mais ambientes, um deles sendo mais rico e com menor equabilidade. Especulamos que um balanço entre padrões mais aleatórios (na FTB) ou mais agregados (na FRS), o ambiente e as interações bióticas possam guardar relações com uma maior ou menor equabilidade. Essa maior equabilidade na FRS compensou a maior riqueza na FTB no cálculo do índice que enfatiza a equabilidade (Simpson), resultando em diferenças não significativas. Quando calculado o índice que enfatiza mais a riqueza (Shannon), a FTB mostrou-se mais diversa, como esperado.

No litoral norte do Estado de São Paulo, a floresta que ocorre sobre os solos arenosos da restinga havia se mostrado muito distinta da floresta que ocorre no sopé da serra, quanto à gênese do solo e à composição florística e estrutura do estrato arbóreo (Assis et al. 2011). As análises conduzidas no presente trabalho corroboram essa distinção, sugerindo fortemente que a composição florística e a riqueza de pteridófitas são diferentes nas duas áreas estudadas. Dada a importância das pteridófitas como indicadores ambientais, as fortes diferenças florísticas encontradas sugerem que os ambientes sejam de fato muito peculiares. Essa disparidade entre áreas de restinga e de sopé de encosta deve ser considerada em trabalhos de restauração florestal na Mata Atlântica.

Estudos adicionais relacionando a microtopografia e aspectos ecofisiológicos tais como capacidade fotossintética e uso de nutrientes, juntamente com os dados de riqueza e abundância de pteridófitas apresentados, podem elucidar possíveis preferências ecológicas das espécies, assim como verificar detalhadamente o papel da dinâmica da água nessa floresta de restinga.

\section{Agradecimentos}

Este trabalho foi financiado pela Fundação de Amparo à Pesquisa do Estado de São Paulo (FAPESP) no âmbito do Projeto Temático Biota Gradiente Funcional: Composição florística, estrutura e funcionamento da Floresta Ombrófila Densa dos Núcleos Picinguaba e Santa Virgínia do Parque Estadual da Serra do Mar (Processo 03/12595-7), que faz parte do Programa BIOTA/FAPESP - O Instituto Virtual da Biodiversidade (www.biota.org.br). Autorização COTEC/IF 41.065/2005 e autorização IBAMA/CGEN 093/2005. Os dois primeiros autores agradecem ao $\mathrm{CNPq}$, pelas bolsas de estudos de Doutorado.

\section{Referências Bibliográficas}

ACKERLY, D.D. 2003. Community assembly, niche conservatism, and adaptive evolution in changing environments. Int. J. Plant Sci. 164 (3 Suppl):165-184. http://dx.doi.org/10.1086/368401

ARENS, N.C. \& BARACALDO, P.S. 1998. Distribution of tree ferns (Cyatheaceae) across the successional mosaic in an andean cloud forest, Nariño, Colombia. American Fern Journal 88:60-71. http://dx.doi. org/10.2307/1547225

ASSIS, M.A., PRATA, E.M.B., PEDRONI, F., SANCHEZ, M., EISENLOHR, P.V., MARTINS, F.R., SANTOS, F.A.M., TAMASHIRO, J.Y., ALVES, L.F., VIEIRA, S.A., PICCOLO, M.C., MARTINS, S.C., CAMARGO, P.B., CARMO, J.B., Martins, L.F.B., SIMÕES, E. \& JOLY, C.A. 2011. A vegetação arbórea da Floresta Ombrófila Densa difere entre a Restinga e as Terras Baixas na Serra do Mar? Biota Neotrop. 11(2): http://www. biotaneotropica.org.br/v11n2/pt/abstract?article+bn02111022011
BARNARDE, N., WILLIAMS-LINERA, G. \& PALACIOS-RIOS, M. 1999. Tree ferns in the interior and at the edge of a mexican cloud forest remnant: spore germination and sporophyte survival and establishment. Biotropica 31:83-88.

BEGON, M., TOWNSEND, C.R. \& HARPER, J.L. 2007. Ecologia de indivíduos a ecossistemas. $4^{\text {nd }}$ ed. Artmed Editora S/A, Porto Alegre.

BREWER, A. \& WILLIAMSON, M. 1994. A new relationship for rarefaction. Biodivers. Conserv. 3:373-379. http://dx.doi.org/10.1007/BF00056509

CONWAY, E. \& STEPHENS, R. 1957. Sporeling establishment in Pteridium aquilinum: effects of mineral nutrients. J. Ecol. 45:389-399. http://dx.doi.org/10.2307/2256925

CREMERS, G. \& KRAMER, K.U. 1991. Dennstaedtiaceae. In Flora of the Guianas (A.R.A.G. Rijn, ed.). Koeltz Scientific Books. Koenigstein, fasc. 4, p.20-81.

DIAS-FILHA, M.C.C. 1989. Aspectos fenológicos e germinação de esporos de Lygodium volubile Sw. (Schizaeaceae). Dissertação de Mestrado, Universidade Federal de Pernambuco, Recife.

DUFRÊNE, M. \& LEGENDRE, P. 1997. Species assemblages and indicator species: the need for a flexible asymmetrical approach. Ecol. Monog. 67:345-366.

DURIGAN, G. 2006. Métodos para análise de vegetação arbórea. In Métodos e estudos em Biologia da Conservação e Manejo da Vida Silvestre (L. Cullen Junior, R. Rudran \& C. Valladares-Pádua, orgs.). $2^{\text {nd }}$ ed. Editora UFPR, Curitiba.

FARIA, D., MARIANO-NETO, E., MARTINI, A.M.Z., ORTIZ, J.V., MONTINGELLI, R., ROSSO, S., PACIÊNCIA, M.L.B. \& BAUMGARTEN, J. 2009. Forest structure in a mosaic rainforest sites: the effect of fragmentation and recovery after clear cut. Forest. Ecol. Manag. 257:226-2234. http://dx.doi.org/10.1016/j.foreco.2009.02.032

FOSTER, R.B. 1990. The floristic composition of the manu foodplain forest. In Four Neotropical Rain Forests (A.H.Gentry, ed.). Yale University Press, New Haven, p.99-111.

FOSTER, R.B. \& HUBBELL, S.P. 1990. Floristic composition of the Barro Colorado forest. In Four Neotropical Rain Forests (A.H.Gentry, ed.). Yale University Press, New Haven, p.85-98

FUNDAÇÃO SOS MATA ATLÂNTICA. 2009. Atlas dos remanescentes florestais da Mata Atlântica Período 2005-2008. Fundação SOS Mata Atlântica/Instituto Nacional de Pesquisas Espaciais, São Paulo.

GENTRY, A.H. 1990. Floristic similarities and differences between Southern Central America and upper and Central Amazonia. In Four neotropical rain forests (A.H. Gentry, ed.). Yale University Press, New Haven, p.141-160.

GRAYUM, M.H. \& CHURCHILL, H.W. 1987. An introduction to the pteridophyte flora of Finca La Selva, Costa Rica. Am. Fern J. 77:73-89. http://dx.doi.org/10.2307/1547496

HAMMEL, B. 1990. The distribution of diversity among families, genera, and habit types in La Selva Flora. In Four Neotropical Rain Forests (A.H.Gentry, ed.). Yale University Press, New Haven, p.75-84

HAMMER, Ø., HARPER, D.A.T. \& RYAN, P.D. 2001. P A S T PAlaeontological Statistics. http://folk.uio.no/ohammer/past/ (último acesso em 15/02/2010).

HILL, M.O., BUNCE, R.G.H. \& SHAW, M.W. 1975. Indicator Species Analysis, a divise polythetic method of classification, and its application to a survey of native pinewoods in Scotland. J. Ecol. 63:597-613. http:// dx.doi.org/10.2307/2258738

HUBBELL, S.P. 2001. The unified neutral theory of biodiversity and biogeography. Princeton University, Press Princeton.

HURLBERT, S.H. 1971. The non-concept of species diversity: a critique and alternative parameters. Ecology 52:577-586. http://dx.doi. org/10.2307/1934145 
JONES, M.M., TUOMISTO, H., CLARK, D.B. \& OLIVAS, P. 2006. Effects of mesoscale environmental heterogeneity and dispersal limitation on floristic variation in rain forest ferns. J. Ecol. 94:181-195. http://dx.doi. org/10.1111/j.1365-2745.2005.01071.x

JONGMAN, R.H.G., TER BRAAK, C.J.F. \& VAN TONGEREN, O.F.R. 1995. Data analysis in community and landscape ecology. $2^{\text {nd }} e d$. Cambridge University Press, Cambridge. http://dx.doi.org/10.1017/ CBO9780511525575

KENT, M. \& COKER, P. 1992. Vegetation description and analysis: a practical approach. John Wiley \& Sons, New York.

KREBS, C.J. 1989. Ecological Methodology. $2^{\text {nd }}$ ed. Harper \& Row, Publ., New York.

LABIAK, P.H. \& PRADO J. 1998. Pteridófitas epífitas da Reserva de Volta Velha, Itapoá-Santa Catarina, Brasil. Bol. Inst. Bot. 11:1-79.

LACERDA, M.S. 2001. Composição florística e estrutura da comunidade arbórea num gradiente altitudinal da Mata Atlântica. Tese de Doutorado, Universidade Estadual de Campinas, Campinas.

LEÓN, B. 1995. Campyloneurum. In Flora Mesoamericana: Psilotaceae a Salviniaceae (R.C. Moran \& R. Riba, eds.). Universidad Nacional Autónoma de México, Ciudad de México, v.1. p.336-337.

LEÓN, B. \& YONG, K.R. 1996. Distribution of pteridophyte diversity and endemism in Peru. In Pteridology in perspective (J.M. Camus, M. Gibby \& R.J. Johns, eds.). Symposium 95, Royal Botanic Gardens, Kew, p. 77-91.

LUDWIG, J.A. \& REYNOLDS, J.F. 1988. Statistical Ecology - a primer on methods and computing. John Wiley \& Sons, New York.

MACARTHUR, R.H. 1957. On the relative abundance of bird species. Proc. Natl. Acad. Sci. USA 43:293-295. http://dx.doi.org/10.1073/ pnas.43.3.293

MAGURRAN, A.E. 2004. Measuring Biological Diversity. Blackwell Publishing, Oxford.

MANLY, B.F.J. 1994. Multivariate statistical methods: a primer. $2^{\text {nd }} \mathrm{ed}$. Chapman \& Hall, London.

MARTINS, F.R. \& SANTOS, F.A.M. 1999. Técnicas usuais de estimativa da diversidade. Holos ed. especial:236-267.

McCUNE, B. \& MEFFORD, M.J. 1999. PC-ORD - multivariate analysis of ecological data. Version 4.0. MjM Software Design, Gleneden Beach.

MORAN, R.C. 1995. Lindsaea. In Flora Mesoamericana: Psilotaceae a Salviniaceae (R.C. Moran \& R. Riba, eds.). Universidad Nacional Autónoma de Mexico, Ciudad de México, v.1, p.158-159.

MYERS, N., MITTERMEIER, R.A., MITTERMEIER, C.G., FONSECA, G.A.B. \& KENT, J. 2000. Biodiversity hotspots for conservation priorities. Nature 403:853-858. http://dx.doi.org/10.1038/35002501

NÓBREGA, G.A. \& PRADO, J. 2008. Pteridófitas da vegetação nativa do Jardim Botânico Municipal de Bauru, Estado de São Paulo, Brasil. Hoehnea 35:7-55.

PACHECO, L. 1995 Trichomanes. In Flora Mesoamericana: Psilotaceae a Salviniaceae (R.C. Moran \& R. Riba, eds.). Universidad Nacional Autónoma de México, Ciudad de México, v.1, p.81-82.

PACIÊNCIA, M.L.B. \& PRADO, J. 2004. Efeitos de borda sobre a comunidade de pteridófitas na Mata Atlântica da região de Una, sul da Bahia, Brasil. Rev. Bras. Bot. 27:641-653.

PACIÊNCIA, M.L.B. \& PRADO, J. 2005a. Effects of the forest fragmentation on the pterydophyte communities in an Atlantic Rain Forest. Plant. Ecol. 180:87-104. http://dx.doi.org/10.1007/s11258-005-3025-x

PACIÊNCIA \& PRADO 2005b. Distribuição espacial da assembléia de pteridófitas em uma paisagem fragmentada de Mata Atlântica no sul da Bahia, Brasil. Hoehnea 32:103-117.
PACIÊNCIA, M.L.B. 2008. Diversidade de pteridófitas em gradientes de altitude na Mata Atlântica do Estado do Paraná, Brasil. Tese de Doutorado, Universidade de São Paulo, São Paulo.

PAYANDEH, B. 1970. Comparison of method for assessing spatial distribution of trees. Forest. Sci. 16:312-317.

PICHI SERMOLLI, R.E.G. 1996. Authors of scientific names in Pteridophyta. Royal Botanic Gardens, Kew.

POULSEN, A.D. \& BASLEV, H. 1991. Abundance and cover of ground herbs in an Amazonian rain forest. J. Veg. Sci. 2:315-322. http://dx.doi. org/10.2307/3235922

POULSEN, A.D. \& NIELSEN, I.H. 1995. How many ferns in there in one hectare of Tropical Rain Forest? Am. Fern J. 85:29-35. http://dx.doi. org/10.2307/1547678

RICCI, M. 1996. Variation in distribution and abundance of the endemic flora of Juan Fernández Island, Chile. Pteridophyta. Biodivers. Conserv. 5:1521-1532. http://dx.doi.org/10.1007/BF00052113

RUOKOLAINEN, K., LINNNA, A. \& TUOMISTO, H. 1997. Use of Melastomataceae and pteridophytes for revealing phytogeographical patterns in Amazoniam rain forests. J. Trop. Ecol. 13:243-256. http://dx.doi.org/10.1017/S0266467400010439

SANDERS, H.L. 1968. Marine benthic diversity: a comparative study. Am. Nat. 102:243-282. http://dx.doi.org/10.1086/282541

SANTIAGO, A.C.P., BARROS, I.C.L. \& SYLVESTRE, L.S. 2004. Pteridófitas ocorrentes em três fragmentos florestais de um brejo de altitude (Bonito, Pernambuco, Brasil). Acta Bot. Bras. 18:781-792. http:// dx.doi.org/10.1590/S0102-33062004000400008

SETZER, J. 1966. Atlas climatológico do estado de São Paulo. Comissão Interestadual da Bacia do Paraná-Paraguai, CESP, São Paulo.

SHEPHERD, G.J. 2009. FITOPAC 2.1 (versão preliminar). Universidade Estadual de Campinas, Campinas.

SIMPSON, E.H. 1949. Measurement of diversity. Nature 163:688. http:// dx.doi.org/10.1038/163688a0

SMITH, E.P. \& VAN BELLE, G. 1984. Nonparametric estimation of species richness. Biometrics 40:119-129. http://dx.doi.org/10.2307/2530750

SMITH, A.R., PRYER, K.M., SCHETTPELZ, E., KORALL, P., SCHEIDER, H. \& WOLF, P. 2006. A classification for extant ferns. Taxon 55:705-731. http://dx.doi.org/10.2307/25065646

SNEATH, P. H. \& SOKAL, R. R. 1973. Numerical taxonomy. Freeman and Company, San Francisco, p.1-575.

TILMAN, D. 1982. Resource competition and community structure. Princeton University Press, Princeton.

TILMAN, D. \& PACALA, S. 1993. The maintenance of species richness in plant communities. In Species Diversity in Ecological Communities: historical and geographical perspectives (R.E. Ricklefs \& D. Schluter). The University of Chicago Press, Chicago. p.13-25

TRYON, R.M. 1972. Endemic areas and geographic speciation in tropical American ferns. Biotropica 4:121-131. http://dx.doi.org/10.2307/2989774

TRYON, R. M. \& TRYON, A. F. 1982. Ferns and allied plants, with special reference to tropical America. Springer Verlag, New York.

TRYON, R. 1986. Biogeography of species, with special reference to ferns. Bot. Rev. 52:117-156. http://dx.doi.org/10.1007/BF02860999

TUOMISTO, H. \& RUOKOLAINEN, K. 1994. Distribution of Pteridophyta and Melastomataceae along an edapic gradient in an Amazonian rain forest. J. Veg. Sci. 5:25-34. http://dx.doi.org/10.2307/3235634

TUOMISTO, H., RUOKOLAINEN, K., KALLIOL, R., LINNA, A., DANJOY, W. \& RODRIGUES, Z. 1995. Dissecting Amazonian biodiversity. Science 269:63-66. http://dx.doi.org/10.1126/science.269.5220.63

TUOMISTO, H. \& POULSEN, A.D. 1996. Influence of edaphic specialization on pteridophyte distribution in Neotropical Rain Forests. J. Biogeogr. 23:283-293. http://dx.doi.org/10.1046/j.1365-2699.1996.00044.x 
TUOMISTO, H., RUONKOLAINEN, K., POULSEN, A.D., MORAN, R., QUINTANA, C., CAÑAS, G. \& CELI, J. 2002. Distribution and Diversity of pteridophytes and Melastomataceae along edaphic gradientes in Yasuní National Park, Ecuadorian Amazonia. Biotropica 34:516-533. http://dx.doi.org/10.1111/j.1744-7429.2002.tb00571.x

TUOMISTO, H., RUOKOLAINEN, K. \& YLI-HALLA, M. 2003. Dispersal, environment, and floristic variation of Western Amazonian Forests. Science 299:241-244.

VELOSO, H.P., RANGEL FILHO, A.L.R. \& LIMA, J.C.A. 1991. Classificação da Vegetação Brasileira, adaptada a um sistema universal. IBGE, Rio de Janeiro.
YOUNG, K.R. \& LEÓN, B. 1989. Pteridophyte species diversity in the central Peruvian Amazon: importance of edaphic specialization. Brittonia 41(4):388-395. http://dx.doi.org/10.2307/2807552

WINDISCH, P.G. 1990. Pteridófitas da Região Norte-Ocidental do Estado de São Paulo - Guia para excursões. UNESP, São José do Rio Preto.

WINDSCH, P.G. 1992. Trichomanes crispum L. (Pteridophyta, Hyenophyllaceae)and allied species. Bradea 6:78-117.

ZUNQUIM, G., COSTA, F.R.C., PRADO J. \& TUOMISTO, H. 2008. Guia de Samambaias e Licófitas da REBIO UATUMÃ, Amazônia Central. Editora Attema, Manaus.

Recebido em 02/03/2010 Versão reformulada recebida em 23/04/2011

Publicado em 03/06/2011 